\title{
Double-hit lymphoma of the male breast: a case report
}

\author{
Shaymaa Elgaafary ${ }^{1,2,3}$, Inga Nagel ${ }^{2,4}$, Cristina López ${ }^{1,2}$, Susanne Bens ${ }^{1,2}$, Monika Szczepanowski ${ }^{5,6}$, \\ Rabea Wagener ${ }^{1,2}$, Wolfram Klapper ${ }^{6}$ and Reiner Siebert ${ }^{1,2^{*}}$
}

\begin{abstract}
Background: Whereas lymphoma of the female breast is already rare, lymphoma of the male breast has only anecdotally been reported. Within a study of 32 lymphoma of the breast reported between 1973 and 2014 as Burkitt lymphoma, we observed a single male case, which we report here.

Case presentation: A 72-years-old Caucasian man presented with a mass in his left breast. Clinical history included prior basal cell carcinoma, leiomyosarcoma, and administration of spironolactone. The reference pathology diagnosis at presentation was Burkitt lymphoma according to the Kiel Classification. The present re-investigation using fluorescence in situ hybridization revealed an IGH-MYC translocation and a break in the BCL2 locus in the tumor cells. Thus, in light of the current WHO classification, the diagnosis was revised to high-grade B-cell lymphoma with MYC and BCL2 rearrangement, Burkitt morphology (so-called "double-hit" lymphoma). Genome-wide chromosomal imbalance mapping revealed a complex pattern of aberrations in line with this diagnosis. The aberrations, including copy-number gains in chromosomes $3 q$ and 18 and focal homozygous loss in 9p21.3, resembled typical changes of lymphomas affecting "immune-privileged" sites.
\end{abstract}

Conclusion: The present case adds to the understanding of the pathogenesis of male breast lymphomas, about which hardly any molecular characterization has been published yet.

Keywords: Lymphoma, MYC, BCL2, breast, male, Burkitt

\section{Background}

Primary lymphoma of the male breast is an extremely rare presentation affecting males in the fourth to seventh decades of life $[1,2]$. To date, less than 50 cases of male breast lymphoma have been reported in the literature [1, 2]. Clinical presentation of breast lymphoma in men usually resembles the more common carcinomas with a mammographically solitary well-circumscribed painless mass in the breast and/or the ipsilateral axillary lymph nodes commonly unilateral [3-8]. Previous reports on male breast lymphomas focused mainly on the clinical

\footnotetext{
* Correspondence: reiner.siebert@uni-ulm.de

${ }^{1}$ Institute of Human Genetics, UIm University and UIm University Medical Center, D-89081 Ulm, Germany

Full list of author information is available at the end of the article
}

and pathological features of the tumor [3-9]. Reports describing the genetic alterations of male breast lymphomas are, to the best of our knowledge, scarce. In the context of a retrospective study aiming at molecularly characterizing 32 lymphomas of the breast diagnosed historically between 1973 and 2014 as Burkitt lymphoma at the Lymph Node Registry in Kiel (Germany), we came across the case of a single male patient, which is presented here.

\section{Case Presentation}

The tumor tissue sample of the at diagnosis 72-year-old Caucasian man was obtained at the Lymph Node Registry in Kiel (Germany) more than 25 years ago. His main complaint was an asymptomatic unilateral progressive mass of his left breast persisting over 3 months. A 
history of basal cell carcinoma and leiomyosarcoma was recorded 25 and 10 years prior to the lymphoma manifestation, respectively. Furthermore, long-term treatment with spironolactone was reported. A clinical examination revealed bilateral non-tender gynecomastia along with a painless swelling in his left breast and testis together with ipsilateral enlarged superficial inguinal lymph nodes. Bilateral mastectomy was performed and reference pathological analyses of the excised tissue led at that time to the diagnosis of Burkitt lymphoma of the breast according to the Kiel Classification. Neither data on treatment nor on outcome were available. During a retrospective survey of breast and ovarian lymphomas historically diagnosed as Burkitt lymphoma at the Lymph Node Registry in Kiel (Germany), archived tumor materials (formalin-fixed, paraffin embedded, [FFPE]) of the case described above were retrieved from the files and investigated applying up-to-date technologies. Use of the archived materials for molecular studies was approved by the Ethics Committee of the Faculty of Medicine, Christian-Albrechts-University of Kiel, Germany (D474/14 and D447/10). Interphase fluorescence in situ hybridization (FISH) studies were performed using the dual color break apart probes, LSI $M Y C$, LSI IGH, LSI $B C L 2$ and LSI BCL6, as well as, the tri-color dual fusion probe LSI IGH/MYC/CEP8 (all probes were obtained from Vysis/Abbott Molecular, Wiesbaden, Germany). Whenever possible at least 100 nuclei were evaluated for each probe. FISH analyses were evaluated and documented using the ISIS digital image analysis version 5.0 (MetaSystems, Altussheim, Germany). For histological evaluation, tumoral tissue was stained with Hematoxylin and Eosin (H\&E), as well as with a panel of monoclonal antibodies for detection of CD20, CD10, BCL2, TdT and Ki67 expression. Moreover, Epstein-Barr virus (EBV) encoded RNA (EBER) in situ hybridization was performed. For the analysis of genome-wide imbalances, DNA was extracted from the FFPE material with the QIAmp DNA FFPE tissue kit, (Qiagen, Hilden, Germany) and processed using the Oncoscan ${ }^{\text {tox }}$ FFPE express 2.0 kit (Affymetrix, Santa Clara, CA, USA). Analyses of copy number aberrations (CNA) and copy neutral loss of heterozygosity (CNN-LOH) were performed using the TuScan algorithm of the Nexus Express for Oncoscan 3 software (Biodiscovery, El Segundo, CA, USA). Human reference genome GRCh37/hg19 was used. Gains and losses smaller than $100 \mathrm{~Kb}$ or encompassing less than 20 probes, as well as $\mathrm{CNN}-\mathrm{LOH}$ smaller than $5000 \mathrm{~Kb}$ or including regions of losses were not considered.

Histopathological re-examination showed a diffuse proliferation pattern of malignant medium-sized Blymphocytes (Fig. 1a), suggestive of mature aggressive Bcell lymphoma of Burkitt type in line with the historic diagnosis relying on the Kiel Classification. The tumor cells stained positive for CD20 and BCL2 (Fig. 1b and c) but negative for TdT, CD10 and EBER. Ki-67 showed non-representative staining most likely due to the aging effect of the stored material and thus, was considered not evaluable for technical reasons.

Molecular cytogenetic analyses using interphase FISH revealed the vast majority of cells in the tissue section to carry a chromosomal breakpoint affecting the MYC locus and an IGH-MYC fusion as well as a chromosomal breakpoint affecting the BCL2 gene locus (Fig. 1d and e). In addition, we detected an extra signal of the non-rearranged allele suggesting a gain of the BCL2 locus. Moreover, we observed a gain but no break of the BCL6 locus. Based on these results and in the light of the current World Health Organization (WHO) classification of lymphoma the diagnosis was revised toward "high-grade B-cell lymphoma with $M Y C$ and $B C L 2$ rearrangements, Burkitt morphology", commonly referred to as "double-hit lymphoma".

Chromosomal imbalance mapping using the Oncoscan ${ }^{\text {tw }}$ platform revealed copy number $(\mathrm{CN})$ gains in 3q13.11-q29 and a trisomy 18 (in line with the observed FISH patterns) and $\mathrm{CN}$ losses in 1q41-q44, 2q31.1, 9p21.3, and 10q21.1. Moreover, CNN-LOH were detected in 3p26.3-q13.11, 9p24.3-p13.3, 15q21.1-q21.3, and 16p13.3 (Fig. 1f). Finally, attempts to perform whole-exome sequencing from the tumor unfortunately failed due to technical reasons likely caused by the limited preservation of the historic tissue.

\section{Discussion}

Primary lymphoma of the breast is extremely rare. In contrast to female breast lymphoma that is assumed to occur in up to $0.05 \%$ of women with breast malignancy [10], presentation of the lymphoma in the male breast has been reported only sporadically in rare cases worldwide $[1,2]$.

In the few reported male cases, like in the patient presented here, breast lymphoma mainly affected men in the middle-to-old age groups [2-8]. Being initially considered as Burkitt lymphoma, we here rendered the diagnosis of a so-called "high-grade B-cell lymphoma with $M Y C$ and $B C L 2$ rearrangements" also called "double-hit lymphoma" with Burkitt morphology. This re-classification sets a note of caution to historic studies on the incidence and biology of Burkitt lymphomas in elderly patients or with unusual presentation.

High-grade B-cell lymphomas with $M Y C$ and $B C L 2$ and/ or $B C L 6$ rearrangements represent a quite recently defined entity of lymphoma with aggressive nature, high genomic complexity and poor prognosis [9]. Double-hit lymphomas 


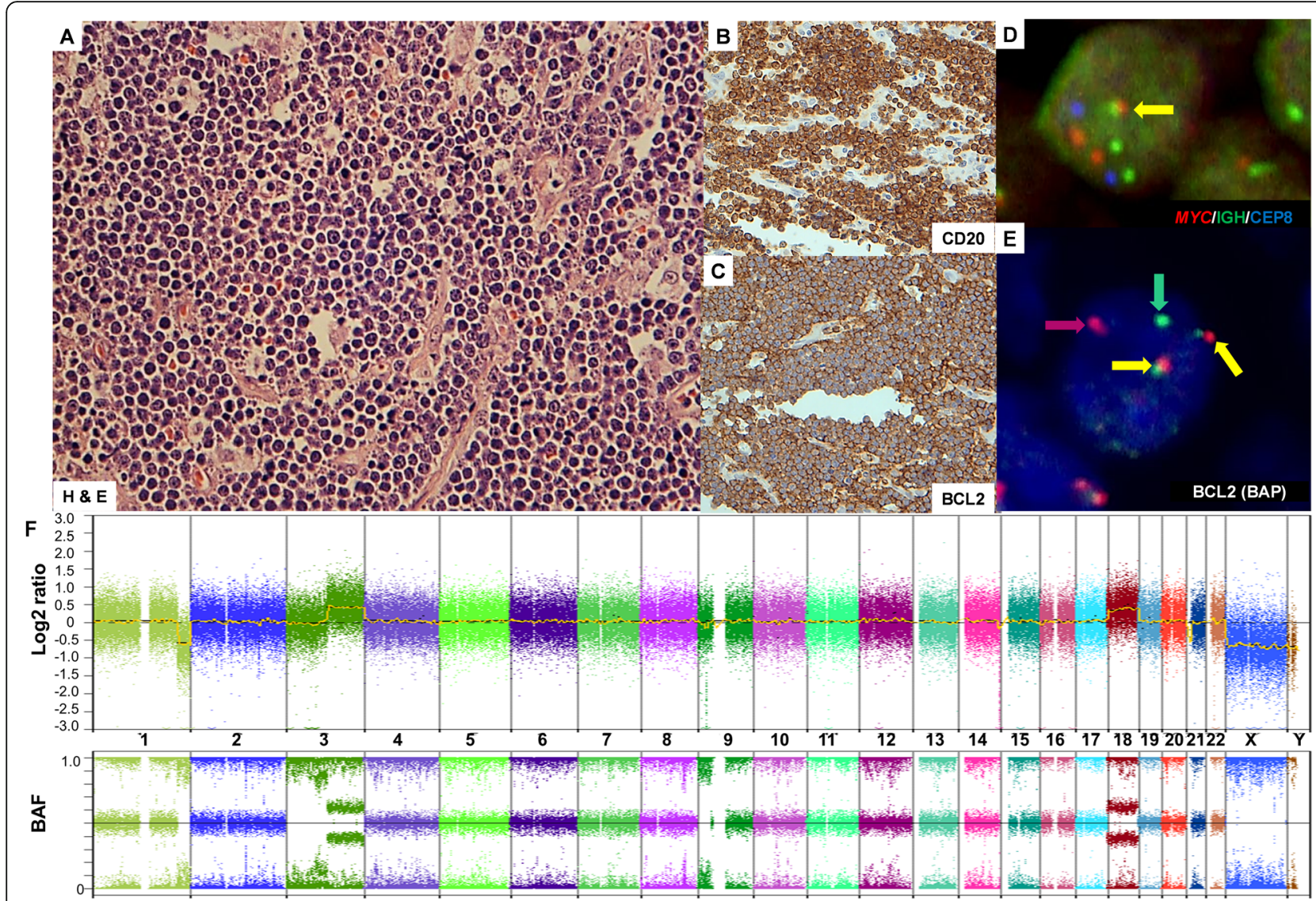

Fig. 1 a Haematoxylin and Eosin (H\&E) staining showing medium-sized lymphocytes with rounded nuclei and deeply basophilic cytoplasm with sporadic diffuse large cells entangling necrotic lymphocytes (magnification 40x). b BCL2 staining (magnification 40X). c CD20 staining (magnification 40x). d-e Interphase FISH in false-color display. (d) LSI MYC (8q24)/ IGH (14q32)/ CEP8, tri-color dual-fusion probe showing one fusion (green and red signals together, indicating by yellow arrow) signal and two red (MYC) and green (IGH) non-fused signals, respectively; and two blue signals of centromere 8. (e) LSI BCL2 (18q21) break-apart probe (BAP) showing two co-localization signals (yellow arrows) and one isolated red and green signal (red and green arrows, respectively) $\mathbf{f}$ Genome-wide log2 ratio copy number aberration plot (top) and B-allele frequency plot (bottom)

comprise between $32 \%$ and $78 \%$ of mature aggressive B-cell lymphoma cases with features intermediate between Burkitt lymphoma and diffuse large B-cell lymphoma [10, 11].

In line with the diagnosis of double-hit lymphoma the complexity of the genomic imbalances depicted by the Oncoscan $^{\text {tw }}$ array was high. The pattern of imbalances showing gains in $3 \mathrm{q}$ and trisomy 18 as well as homozygous loss in 9p21.3 (encompassing the region of $C D K N 2 A / B)$ together with the lack of detectable CD10 in the presence of CD20 and BCL2 expression resembles other extra-nodal lymphoma. This holds particularly true for aggressive B-cell lymphomas at immuneprivileged sites, like primary CNS lymphomas (PCNSL) or testicular lymphomas $[12,13]$. The causes for this rare manifestation in the patient presented here remain unclear. Nevertheless, it is intriguing to speculate that there might be an association with the former spironolactone treatment, well known to induce gynecomastia. Alternatively, based on the clinical history of the patient with multiple neoplasia, a tumor predisposition syndrome could underly lymphoma development. Unfortunately, we could not investigate the latter hypothesis as the tumor material was of insufficient quality for wholeexome analysis.

\section{Conclusion}

In conclusion, we described a rare EBV-negative highgrade B-cell lymphoma with $M Y C$ and $B C L 2$ rearrangements of the male breast. The similarities of the molecular findings to other types of non-nodal aggressive B-cell lymphoma affecting immune-privileged sites might indicate common pathogenetic mechanisms.

\section{Abbreviations}

BCL2: B-cell lymphoma 2; BCL6: B-cell lymphoma 6; CD20, CD10: Cluster of differentation 20, cluster of differentiation 10 (markers of B-cell maturity); CDKN2A/B: Cyclin-dependent kinase inhibitor 2A/B; CEP8: Chromosome enumerator probe 8 (Centromeric probe of chromosome 8); CN: Copy number; CNA: Copy number aberration; CNN-LOH: Copy neutral loss of heterozygosity; DNA: deoxyribonucleic acid; EBER: Epstein-Barr virus-encoded 
RNA; EBV: Epstein-Barr virus; FFPE: Formalin-fixed, paraffin-embedded; FISH: Fluorescence in situ hybridization; H \&E: Hematoxylin and Eosin; IGH: Immunoglobulin heavy chain; ISIS: name of Software for FISH from MetaSystem; Ki-67: Marker of cell proliferation; Kb: kilobase; LSI: Locus-specific identifier; MYC: Cellular myelocytomatosis gene; NCBI: National Center for Biotechnology Information; PCNSL: Primary central nervous system lymphoma; TdT: Terminal deoxynucleotidyl transferase; USA: United States of America; WHO: World Health Organization

\section{Acknowledgements}

We acknowledge the excellent technical assistance of the members of the tumor genetics lab at the Institutes of Human Genetics in Kiel, particularly R. Zühlke-Jenisch, U. Schade, P. Kozak, C. Becher, G. Riesen, and L. Valles, and Ulm, as well as the team of the Lymph Node Registry Kiel, O. Batic, and S. Pietz.

Footnote

The present address of SE is: Gynecological Oncology, Nationales Zentrum für Tumorerkrankungen (NCT), University Hospital Heidelberg and Deutsches Krebsforschungszentrum (DKFZ), Heidelberg, Germany. The present address of RW is: Department of Pediatric Oncology, Hematology and Clinical Immunology, University Children's Hospital, Medical Faculty, Heinrich-HeineUniversity Düsseldorf, Düsseldorf, Germany.

\section{Authors' contributions}

SE identified the case, performed the analyses, and drafted the manuscript. IN reviewed the fluorescence in situ hybridization, interpreted data, corrected and approved the manuscript. CL reviewed the fluorescence in situ hybridization, interpreted data, corrected and approved the manuscript. SB reviewed the fluorescence in situ hybridization, interpreted data, corrected and approved the manuscript. MS reviewed of the histopathological analyses and immunohistochemical staining, interpreted data, corrected and approved the manuscript. RW reviewed the genome-wide copy number data, interpreted data, corrected and approved the manuscript. WK conceived and supervised the study, performed the histopathological review, corrected and approved the manuscript. RS conceived and supervised the study and drafted the manuscript.

\section{Funding}

This research has been conducted in the framework of the e:BIO project Molekulare Mechanismen in Malignen Lymphomen mit MYC-Deregulation (MMML-MYC-SYS) funded by Bundesministerium für Bildung und Forschung (BMBF) via grant 0316166l. The DAAD (Deutscher Akademischer Austausch Dienst) and the KinderKrebsInitiative Buchholz Holm-Seppensen are gratefully acknowledged for support.

Open Access funding enabled and organized by Projekt DEAL.

\section{Availability of data and materials}

The datasets used and/or analyzed during the current study are available from the corresponding author on reasonable request.

\section{Ethics approval and consent to participate}

Ethical approval for the study was obtained from the Ethical Committee of the Faculty of Medicine of Christian-Albrechts University of Kiel (number D474/14 with reference to $447 / 10$ ).

\section{Consent for publication}

We declare that the study was performed in accordance with the guidelines of the ethics committee but, based on the historic nature of this case, we cannot provide a signature of patient or relative.

\section{Competing interests}

The authors have no competing interest to declare.

\section{Author details}

'Institute of Human Genetics, UIm University and UIm University Medical Center, D-89081 Ulm, Germany. ${ }^{2}$ Institute of Human Genetics,

Christian-Albrechts University Kiel and University Hospital Schleswig-Holstein, Campus Kiel, D-24105 Kiel, Germany. ${ }^{3}$ Division of Human Genetics and Genome Research, Department of Human Cytogenetic, Cairo 12622, Egypt. ${ }^{4}$ Institute of Experimental and Clinical Pharmacology, Christian-Albrechts University Kiel and University Hospital Schleswig-Holstein Campus Kiel,
D-24105 Kiel, Germany. ${ }^{5}$ Department of Internal Medicine II (Hematology), Laboratory of Hematology, University Hospital, Schleswig-Holstein Campus Kiel, D-24105 Kiel, Germany. ${ }^{6}$ Hematopathology Section and Lymph Node Registry, Institute of Pathology Christian-Albrechts University Kiel and University Hospital Schleswig-Holstein, Campus Kiel, D-24105 Kiel, Germany

Received: 18 June 2020 Accepted: 8 September 2020

Published online: 18 December 2020

\section{References}

1. Davies A. Double-hit lymphoma: So what? Hematol Oncol. 2019;37(1):19-23.

2. Lokesh $\mathrm{KN}$, Sathyanarayanan $\mathrm{V}$, Lakshmaiah $\mathrm{KC}$, Suresh $T M$, Lokanatha $D$, Babu KG, et al. Primary breast lymphoma in males - a report of two cases with a review of the literature. Ecancermedicalscience. 2013;7:347,1-4.

3. Luanow $E$, Kettler M, Slanetz PJ. Spectrum of disease in the male breast. AJR. 2011;196:W247-59.

4. Cheah CY, Campbell BA, Seymour JF. Primary breast lymphoma. Cancer Treat Rev. 2014;40(8):900-8

5. Corobea AB, Dumitru A, Sajin M, Poenaru R, Puşcaşu A, Chirita D, et al. Diffuse large $b$ cell lymphoma in a male breast - a rare case report. Chirurgia (Bucur). 2017;112(4):477-81.

6. Sordi E, Cagossi K, Lazzaretti MG, Gusolfino D, Artioli F, Santacroce G, et al. Rare case of male breast cancer and axillary lymphoma in the same patient: a unique case report. Case Rep Med. 2011;2011:940803,1-4.

7. Yim B, Park JS, Koo HR, Kim SY, Choi YY, Kim JY, et al. Primary breast lymphoma in an immunocompromised male patient: a case report. J Korean Soc Radiol. 2015;73(4):264-8.

8. Zheng $\mathrm{G}, \mathrm{Yu} \mathrm{H}$, Hemminki A, Fo A. Familial associations of male breast cancer with other cancers. Breast Cancer Res Treat. 2017;166(3):897-902.

9. Swerdlow SH, Campo E, Pileri SA, Harris NL, Stein H, Siebert R, et al. The 2016 revision of the World Health Organization classification of lymphoid neoplasms. Blood. 2016;127(20):2375-90.

10. Swerdlow SH. Diagnosis of 'double hit' diffuse large B-cell lymphoma and Bcell lymphoma, unclassifiable, with features intermediate between DLBCL and Burkitt lymphoma: when and how, FISH versus IHC. Hematol Am Soc Hematol Educ Program. 2014;2014(1):90-9.

11. Barrans S, Crouch S, Smith A, Crouch S, Smith A, Turner K, et al. Rearrangement of MYC is associated with poor prognosis in patients with diffuse large B-cell lymphoma treated in the era of rituximab. J Clin Oncol. 2010;28(20):3360-5.

12. Batlevi C, Rapaport F, Wang L, Intlekofer AM, Copeland AR, Jungbluth AA, et al. Distinctive genomic alterations in testicular diffuse large b cell lymphoma. Blood. 2015;126(23):3655.

13. Chapuy B, Roemer MGM, Stewart C, Tan Y, Abo RP, Zhang L, et al. Targetable genetic features of primary testicular and primary central nervous system lymphomas. Blood. 2016;127(7):869-81.

\section{Publisher's Note}

Springer Nature remains neutral with regard to jurisdictional claims in published maps and institutional affiliations.

Ready to submit your research? Choose BMC and benefit from

- fast, convenient online submission

- thorough peer review by experienced researchers in your field

- rapid publication on acceptance

- support for research data, including large and complex data types

- gold Open Access which fosters wider collaboration and increased citations

- maximum visibility for your research: over $100 \mathrm{M}$ website views per year

At $\mathrm{BMC}$, research is always in progress.

Learn more biomedcentral.com/submissions 